Ana Lúcia Costa1, João Brás', Rui Sousa', David Teixeira1, Alberto Marques', Bruna Melo1,

Carla Alves Pereira', Sofia Ribeiro Pereira', Ana Isabel Oliveira', Jorge Humberto Silva'

1. Department of Psychiatry and Mental Health, Centro Hospitalar Tondela-Viseu, EPE., Viseu, Portugal.

\title{
BACKERDUND AND AIMS
}

In 1977, at the time called Mental Health Center of Viseu, it was pioneered through the creation of their Community Mental Health Service (CMHS). Deinstitutionalization of the mentally ill and promoting the integration into their communities was the aim of the work developed.

Today it still works every day, with two teams, consisting each of a nurse and a driver, who go out

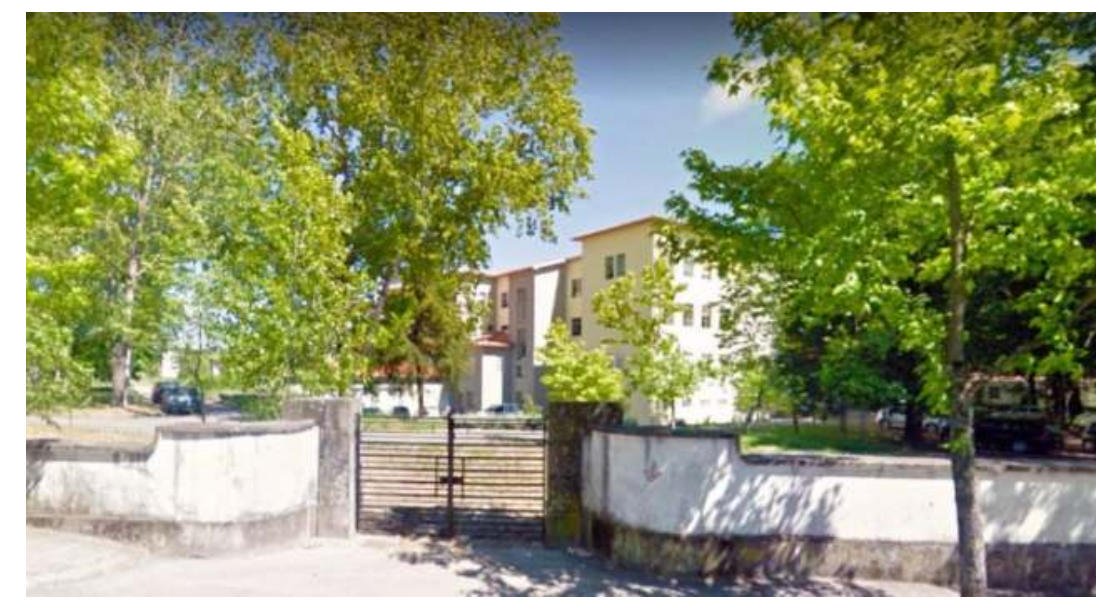
to the street. They travel without a gown and carry only the suitcase containing the necessary medication.

\section{DBJERTIVES}

To present a non-systematic review of literature about the CMHS and to conduct a descriptive analysis of the patient population followed by the CMHS in the Department of Psychiatry and Mental Health of Centro Hospitalar Tondela-Viseu.

\section{MATERIAL AND METHDDS}

Descriptive analysis. Data collected from the clinical files from January to March 2019, analyzed in the program EXCEL ® 2016.

\section{RESULTS}

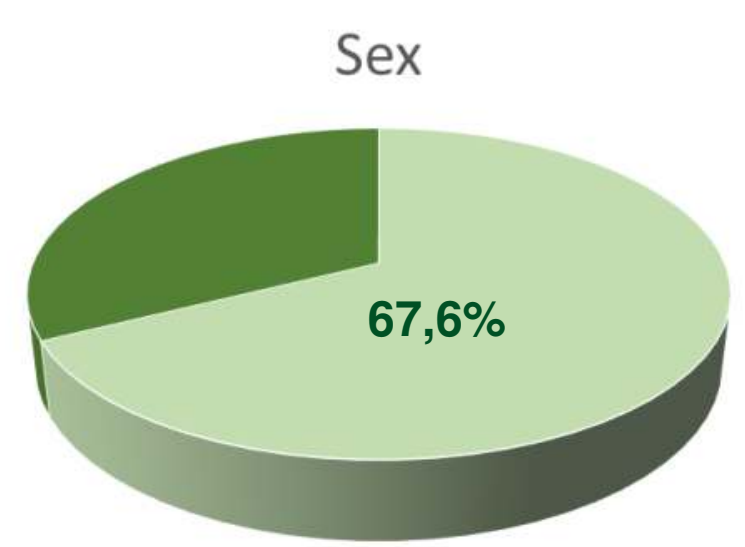

male - Female

DIAGNOSIS (ACCORDING TO ICD-10)

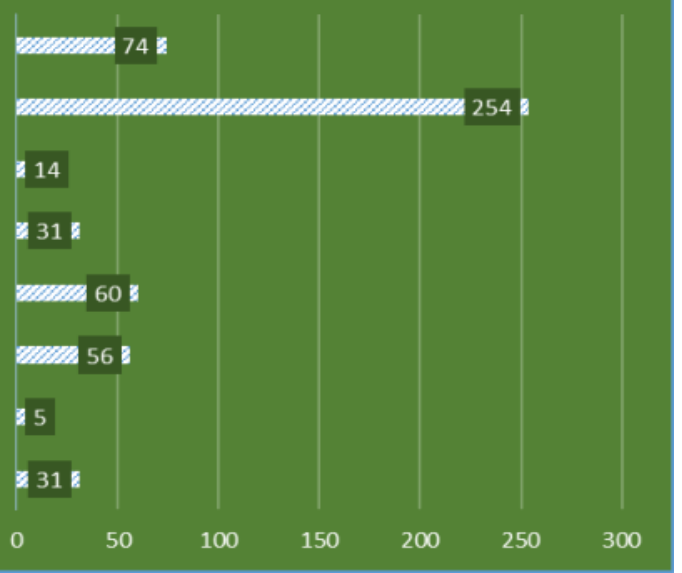

AGE

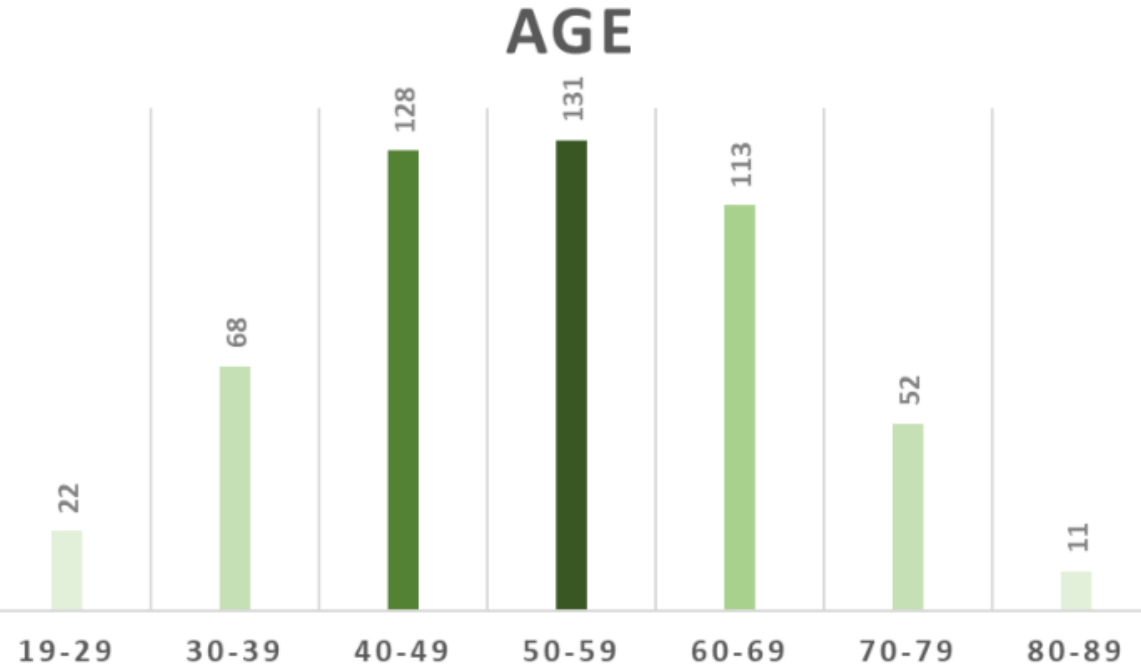

Type of Treatment

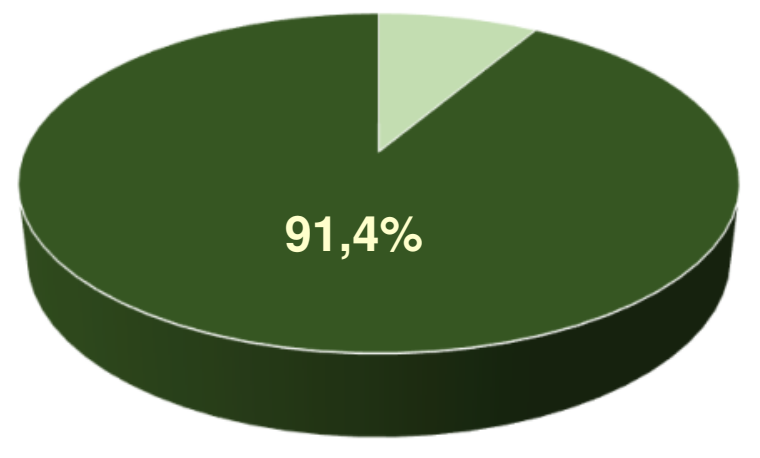

- Compulsive Treatment - Voluntary Treatment

The CHMS currently integrates 525 patients. The patient profile is a man (67.6\%), single $(50.9 \%)$, aged between $50-59$ years $(25 \%)$, with the diagnosis of schizophrenic psychosis (48.4\%) and medicated with Haloperidol decanoate $(76.8 \%)$ plus other drugs $(63.4 \%)$ and in a voluntary treatment $(91,4 \%)$.

\section{CONELISIDN}

The CMHS has progressively assumed a more relevant importance by creating conditions to give dignity and equality to those who suffer from chronic mental illness. Despite most of patients are treated with first-generation antipsychotic long-acting injections, in part due to the economic and financial difficulties that patients have gone through as well as the National Health Service in Portugal, in the last years we are witnessing a growth in the use of second-generation antipsychotic long-acting injections.

Above all, this service has contributed to the reduction of stigma regarding the patient and mental illness and to reduce the number of relapses and hospitalizations. Community psychiatry is no more than treating people with mental illness in their social environment, with their family at home. 